\title{
Socioeconomic Factors Associated with Knowledge on Tuberculosis among Adults in Ethiopia
}

\author{
Sifrash Meseret Gelaw ${ }^{1,2}$ \\ ${ }^{1}$ Unit 12 A, Tuscany Condo, Ayala Avenue 6751, Makati City, 1226 Metro Manila, Philippines \\ ${ }^{2} 24$ th Floor Citibank Tower, Paseo De Roxas 8741, Makati City, 1226 Metro Manila, Philippines \\ Correspondence should be addressed to Sifrash Meseret Gelaw; sifrashm@yahoo.com
}

Received 14 October 2015; Revised 22 December 2015; Accepted 22 December 2015

Academic Editor: Isamu Sugawara

Copyright ( 2016 Sifrash Meseret Gelaw. This is an open access article distributed under the Creative Commons Attribution License, which permits unrestricted use, distribution, and reproduction in any medium, provided the original work is properly cited.

Background. Ethiopia is among highly tuberculosis affected countries. This might be related to low level of awareness on the disease in the population. The objective of the study was to determine the level of tuberculosis knowledge and socioeconomic factors associated with it. Methods. The 2011 Ethiopia health and demographic survey data were used. Overall tuberculosis knowledge score was computed to evaluate the outcome variable. Multivariable logistic regression was employed to identify independent socioeconomic factors associated with low tuberculosis knowledge. Results. The overall tuberculosis knowledge was low, $44.05 \%$ (95\% CI: 42.05-46.24\%) among women and 32.3\% (95\% CI: 30.34-34.32\%) among men. Rural women (AOR = 1.22) and youth, no formal education (women: $\mathrm{AOR}=3.28$, men: $\mathrm{AOR}=7.42$ ), attending only primary education (women: $\mathrm{AOR}=1.95$, men: $\mathrm{AOR}=3.49$ ), lowest wealth quintiles (women: $\mathrm{AOR}=1.4$, Men: $\mathrm{AOR}=1.28)$, unskilled female manual workers $(\mathrm{AOR}=4.15)$, female agricultural employee $(\mathrm{AOR}=2.28)$, and lack of access to media (women: $\mathrm{AOR}=1.52$, men: $\mathrm{AOR}=1.71)$ are significantly associated with low tuberculosis knowledge. Conclusion. The level of tuberculosis knowledge among adults in Ethiopia is low and varied by socioeconomic groups. Tuberculosis control programs should consider appropriate strategies for tuberculosis education, promotion, communication, and social mobilization to address the rural women, youths, the poor, less educated people, and unskilled workers.

\section{Introduction}

Tuberculosis (TB) is a widely recognized high-burden infectious disease in the world. It is a bacterial infection caused by a member Mycobacterium TB complex, commonly Mycobacterium tuberculosis. TB is transmitted by respiratory route when a patient is coughing or sneezing, and one strain of TB, Mycobacterium bovis, can be caused by drinking unboiled milk [1]. Risk of TB is high among population living in poverty, low socioeconomic groups, low income, immune-suppressed (including AIDS), and extreme age (old age and children) groups, certain ethnicity, migrants, and those exposed to animals (Mycobacterium bovis) $[1,2]$. The risk of TB transmission also increases with the intimacy and duration of contact to TB patients and infectiousness of the TB patients [1].

Ethiopia is the second populous country in Africa with a population size of 88 million (July 2014 projection). Only 16\% of the population lives in urban areas and the literacy rate is $42.7 \%[3,4]$. The country is one of the tuberculosis highburden countries, standing on rank 8 under the 22 high TB burden countries in the world with an estimated prevalence and incidence rate of 394 and 261 cases per 100,000 inhabitants, respectively $[5,6]$. The country begun to implement DOTS strategy in 1992. However, only approximately 60 to $70 \%$ of the population has access to DOTS services by 2005 [7, 8]. One of the major problems in controlling the TB burden is the poor awareness and knowledge of the population on $\mathrm{TB}$ $[9,10]$.

Low level of knowledge on TB can lead to complications and worse health outcomes increasing the transmission and delaying health seeking behavior, lack of adherence, resulting in multidrug resistance, treatment failure, and disease complication and death [11-13].

TB control could be significantly improved if more consideration was given to the population's knowledge and 
attitudes about TB and related health care-seeking behavior by directing efforts towards making individuals more informed and aware of all aspects of TB [14-16]. Advocating for the health of patients and developing policy to increase health literacy among the general public as well as health care professionals will create a supportive environment where optimal TB-related outcomes can be achieved [12, 17-20].

Different studies from different countries show the significance of the problem of low TB knowledge and the different socioeconomic factors associated with low TB knowledge in the different study populations. But on the other hand most studies done on TB knowledge in Ethiopia [9, 10, 17-22] as well as studies in different other high TB burden countries [23-29] are done among restricted population subgroups and are mainly health facility based studies which may overestimate the magnitude of the level of knowledge on TB and may not reflect the actual situation in the general population. Moreover, the TB knowledge components considered in these studies were not comprehensive items. These demonstrated the need for exploring large scale comprehensive community level study to recognize the different factors associated with knowledge on TB with the context of Ethiopian culture and socioeconomic status. Further detail analysis of large scale data will help to understand the level of knowledge on TB and associated factors at the country level, which will further guide to design evidence based country appropriate policy, strategy, intervention, service provision, and advocacy to enhance the TB control program. The aim of this study is to identify level of knowledge and socioeconomic factors associated with TB awareness and knowledge about TB transmission, TB symptoms, and TB treatment among adult population of Ethiopia.

\section{Methods}

To address the objectives of the study, secondary analysis of the 2011 Ethiopia Demographic and Health Survey (EDHS) was employed. The survey has used a cross-sectional study design. The survey interviewed a nationally representative sample population in 18,500 households involving 16,515 women aged 15-49 and 14,110 men aged 15-59 from all selected households. A stratified, two-stage cluster sampling method was used. Stratification was achieved by separating each region into urban and rural areas. In the first stage, 624 Enumeration Areas (EAs) were selected with probability proportional to the EA size and with independent selection in each sampling stratum. In the second stage, a fixed number of 30 households were selected for each EA. The survey used three questionnaires: the Household Questionnaire, the Woman's Questionnaire, and the Man's Questionnaire. The questionnaires were pretested, and consent was taken. Interviewers and supervisors were properly trained. A quality control team regularly visited the fieldwork to closely supervise and monitor field activities [3].

Due to the nonproportional allocation of the sample to the different regions and to their urban and rural areas, sampling weights are required for any analysis using 2011 EDHS data to ensure representativeness of the survey results at the national and regional level. Since the 2011 EDHS sample is a two-stage stratified cluster sample, sampling weights were calculated based on sampling probabilities separately for each sampling stage and for each cluster [3].

2.1. Data Management. Information on TB knowledge and socioeconomic factors was extracted from the large dataset. The different datasets for women and men were explored, variables relevant for the current study were identified, and the variables between the women and men dataset were harmonized. To have comparable age distribution between women and men, those with only 15-49 years were included in the analysis. Then the two datasets were matched to produce a subset of the original variables. The extracted data became the working dataset to address the objectives of the project.

2.2. Data Preparation. STATA version 12 was used to analyse the data. Exploration of the variables was made. Data were checked for errors by summarizing and producing frequencies and cross tabulations. Missing values were checked, identified, decoded, and excluded from the analysis.

\subsection{Data Analysis Method}

2.3.1. Descriptive Analysis. Background characteristics of respondents were summarized and presented in tables. Absolute numbers and percentages are displayed. The proportion of respondents who are aware of $\mathrm{TB}$ and who have correct knowledge on $\mathrm{TB}$ transmission, $\mathrm{TB}$ symptoms, and $\mathrm{TB}$ treatment was calculated.

2.3.2. Outcome Measure. The outcome variable, low comprehensive TB knowledge was measured as a composite indicator by considering responses related to TB awareness, modes of transmission, sign and symptoms, and treatment. Questions correctly answered were coded as "1" and incorrect answers as " 0 " during analysis. The lower terciles of the overall summary score were taken as low TB knowledge. The methodological approach in this study is based on different previous similar studies $[9,15]$. In this study, the level of comprehensive $\mathrm{TB}$ knowledge was measured as the main outcome of interest. All the components of TB knowledge such as knowledge on TB transmissions, symptoms, and treatment are included as all the components are relevant with regard to their contribution to $\mathrm{TB}$ prevention and control as described above. Moreover, using an overall composite score allows straight forward comparison of TB knowledge among its different determinant factors. Since there was no study found on psychometric properties of DHS TB knowledge items, factor analysis was employed to examine the psychometric properties of the overall knowledge score.

2.3.3. Factor Analysis and Measuring the Reliability of the Summary Scores. The factor structure of the different knowledge question items was investigated using Principal Components Analysis (PCA), to get clearance on the different dimension of the overall score index. A total of 15 items regarding assessing 
TB knowledge were included in the PCA. Factors with eigenvalue $>1$ were retained. Accordingly, five factors were identified and then rotation was done. Three variables with rotated loading factor less than 0.4 were omitted (these are transmission through sharing utensils, transmission through touching a person with $\mathrm{TB}$, and the fact that tuberculosis can be cured). One variable which was loading on a factor but that was not interpretable was omitted (transmission through exposure to cold). In addition, an initial Cronbach Alpha was calculated (for the whole summary score) and for each variable an alternative alpha if a variable was sorted out was computed. One variable was omitted because the alternative alpha is higher than the initial alpha (transmission through sexual contact). A total of five variables were excluded. Cronbach's Alpha was calculated for checking consistency of the variables and found to be 0.62 . This value is because an index of ten variables is quite small and alpha is dependent on the number of variables in the index. The value of alpha increased to 0.7 as the number of variables increased to fifteen. An overall summary score was calculated using raw values of the remaining variables with rotated factor loading greater than 0.4 on at least one interpretable factor. The lower terciles of the summary score were taken as the outcome measure (low TB knowledge).

From the above factor analysis result, four interpretable factors remained for the overall index construction. These factors are interpreted and qualitatively described as follows. The first component with three items is interpreted as "cough related symptoms and transmissions." The second component with two items is interpreted as "food related symptoms and transmissions." The third component with three items is interpreted as "key symptoms and transmissions." The last component with two items is interpreted as "misconceptions."

2.3.4. Independent Variables. The following different socioeconomic factors are taken as independent variables in the analysis in this study: gender categorized as female and male; age in ten-year intervals; regions categorized into accessible regions (Tigray, Amhara, Oromiya, and SNNPR), hard to reach regions (Afar, Somali, Gambela, and Benishangul Gumuz), and city administrations and regions (Addis Ababa, Dire Dawa, and Harari); residence classified as urban and rural; wealth index (which was already calculated in the primary study based on a standard set of household assets, dwelling characteristics, and ownership of consumer items) categorized in to five where the first quintile was the poorest $20 \%$ of the households and fifth quintile the wealthiest $20 \%$ of the households; marital status classified as never in union, married, living with partner, widowed, divorced, and no longer living together/separated; education categorized into no education, primary, secondary, and more than secondary; occupational status classified as not working, professional/technical/managerial, clerical, sales and services, agricultural employee, skilled manual, and unskilled manual; frequency of exposure to mass media classified as reading newspaper, watching television, and listening radio; and exposure to community conversation program as yes and no response [3].
2.3.5. Assessing Magnitude of Low TB Knowledge. Proportion of adults with low comprehensive TB knowledge was determined along with the corresponding 95\% confidence interval ( $95 \%$ CI) at national and regional level as well as for urban and rural areas. The outcome measure, low comprehensive TB knowledge, was tabulated against socioeconomic factors. All analysis was stratified by sex, since there may be multiple interactions between sex and other independent variables.

2.3.6. Bivariate and Multivariate Analysis of Association. Crude odds ratios (OR) along with the corresponding 95\% confidence intervals were estimated using Mantel-Haenszel method to assess the association between the outcome of interest and each exposure factor. STATA SVY prefix command and weights were used to account for the complex sampling nature of the survey.

Binary logistic regression was employed to further analyse the data. The variables for subsequent analysis in the logistic regression model were selected based on prior information from the literature and/or statistical plausibility $(p<0.05$ in the bivariate analysis). Forward logistic regression strategy was used for building the multivariate logistic regression model step by step.

In addition, interaction terms for effect modifiers were checked. Multicollinearity between independent variables was resolved by computing the collinearity matrix index. The likelihood ratios and the pseudo- $R^{2}$ in the STATA output of the final fit of the multivariable logistic regression model were checked and recorded to see the improvement of the model due to the independent variables included and the estimation of proportion of variability explained by the model. Crude and adjusted odds ratios along with their 95\% confidence interval were presented. Associations were declared significant, if $p<0.05$.

2.3.7. Ethical Considerations. The project was approved by the Ethics Committee of LSHTM. The data source is a secondary human dataset from EDHS 2011. The primary EDHS 2011 has received clearance from the responsible bodies in Ethiopia. MEASRE DHS has given permission to further analyse the data and use it for the current study. There is no personal identifier attached to the dataset.

\section{Results}

3.1. Socioeconomic Characteristics. There were a total of 30,625 study participants in the dataset, of which 16,515 (53.9\%) were women and 14,110 (46.1\%) were men.

Majority, $68.8 \%$, were from rural area and about half, $49.3 \%$, were from the accessible regions (Tigray, Amhara, Oromia, and SNNPR). The age ranged from 15 to 49 years and $40.9 \%$ were 15 to 24 years of age. More than half (55.6\%) were married and 32.9\% have never been in union. About $41.6 \%$ of the participants had no formal education and $40.9 \%$ had only primary education. Almost one-third of the participants had no work and $38.3 \%$ were agricultural employees. About one in four (26.4\%) had no access to newspaper, television, or radio. More than half (58.7\%) of the participants have never heard of community conversions on various topics (Table 1). 
TABLE 1: Background characteristics of respondents, Ethiopia 2011.

\begin{tabular}{|c|c|c|c|}
\hline Characteristics & Category & Number & Percentage \\
\hline \multirow{2}{*}{ Gender } & Female & 16,515 & 53.9 \\
\hline & Male & 14,110 & 46.1 \\
\hline \multirow{2}{*}{ Residence } & Urban & 9,545 & 31.2 \\
\hline & Rural & 21,080 & 68.8 \\
\hline \multirow{4}{*}{ Age } & $15-24$ & 12,019 & 40.9 \\
\hline & $25-34$ & 9,241 & 31.5 \\
\hline & $35-44$ & 6,061 & 20.6 \\
\hline & $45-49$ & 2,062 & 7.0 \\
\hline \multirow{6}{*}{ Current marital status } & Never in union & 10,066 & 32.9 \\
\hline & Married & 17,017 & 55.6 \\
\hline & Living with partner & 1,117 & 3.7 \\
\hline & Widowed & 679 & 2.2 \\
\hline & Divorced & 1,220 & 4.0 \\
\hline & No longer living together/separated & 526 & 1.7 \\
\hline \multirow{3}{*}{ Region } & Accessible regions & 15,092 & 49.3 \\
\hline & Hard to reach regions & 8,388 & 27.4 \\
\hline & City administrations and Harari region & 7,145 & 23.3 \\
\hline \multirow{4}{*}{ Education } & No education & 12,727 & 41.6 \\
\hline & Primary & 12,529 & 40.9 \\
\hline & Secondary & 3,021 & 9.9 \\
\hline & More than secondary & 2,348 & 7.7 \\
\hline \multirow{5}{*}{ Wealth quintile } & Lowest & 6,558 & 21.4 \\
\hline & Second & 4,511 & 14.7 \\
\hline & Middle & 4,422 & 14.4 \\
\hline & Fourth & 4,909 & 16.0 \\
\hline & Highest & 10,225 & 33.4 \\
\hline \multirow{6}{*}{ Occupation } & Not working & 9,183 & 30.3 \\
\hline & Professional/technical/managerial & 1,199 & 4.0 \\
\hline & Clerical/sales/services & 5,517 & 18.2 \\
\hline & Agricultural employee & 11,608 & 38.3 \\
\hline & Skilled manual & 2,431 & 8.0 \\
\hline & Unskilled manual & 404 & 1.3 \\
\hline \multirow{2}{*}{ Exposures to mass media } & Accesses either newspaper, TV, or radio less than or at least once a week & 22,455 & 73.6 \\
\hline & Access none of the three media & 8,065 & 26.4 \\
\hline \multirow{2}{*}{$\begin{array}{l}\text { Heard of community conversation } \\
\text { program }\end{array}$} & No & 17,959 & 58.7 \\
\hline & Yes & 12,652 & 41.3 \\
\hline \multirow{4}{*}{$\begin{array}{l}\text { Last time attended community } \\
\text { conversation meeting }\end{array}$} & Never attended & 2,977 & 23.6 \\
\hline & Within last 3 months & 3,598 & 28.5 \\
\hline & 4-11 months ago & 1,478 & 11.7 \\
\hline & One year or more ago & 1,657 & 13.1 \\
\hline
\end{tabular}

3.2. Awareness and Correct Knowledge about TB. Awareness on TB is high, with $15,045(89.9 \%)$ of women and 13,518 (95.1\%) of men and overall 28,563 (92.3\%) mentioning they had "heard of an illness called tuberculosis (TB)." But only $49.97 \%$ of women and $61.84 \%$ of men knew that TB is transmitted "by air when coughing or sneezing." There were misconceptions of TB transmission; the common misconception was TB transmission by "sharing utensils" and by "exposure to cold," with overall correct responses rate of $68.71 \%$ and $79.6 \%$, respectively. Surprisingly, only $1.82 \%$ of females and $2.55 \%$ of males knew that drinking unboiled milk can cause tuberculosis. Very small proportion of participants 
TABLE 2: TB awareness and respondents correct knowledge on TB transmission, symptoms, and treatment, Ethiopia 2011.

\begin{tabular}{|c|c|c|c|c|}
\hline Characteristics & Characteristics (correct response) & $\begin{array}{c}\text { Women } \\
n(\%)\end{array}$ & $\begin{array}{c}\text { Men } \\
n(\%)\end{array}$ & $\begin{array}{l}\text { Total } \\
n(\%)\end{array}$ \\
\hline Awareness & Heard of tuberculosis or TB (yes) & $15,045(89.92)$ & $13,518(95.09)$ & $28,563(92.3)$ \\
\hline \multirow{8}{*}{$\begin{array}{l}\text { Transmission: } \\
\text { tuberculosis spread } \\
\text { by }\end{array}$} & Air when coughing or sneezing (yes) & $8,644(49.97)$ & $9,036(61.84)$ & $17,680(55.44)$ \\
\hline & Sharing utensils (no) & $11,568(71.6)$ & $8,673(65.33)$ & $20,241(68.71)$ \\
\hline & Touching a person with TB (no) & $14,864(92.32)$ & $12,587(90.74)$ & $27,451(91.59)$ \\
\hline & Food (no) & $15,284(93.5)$ & $13,093(93.03)$ & $\begin{array}{l}28,377 \\
(93.29)\end{array}$ \\
\hline & Sexual contact (no) & $15,656(95.94)$ & $13,513(96.97)$ & $29,169(96.42)$ \\
\hline & Mosquito bites (no) & $16,379(99.47)$ & $13,958(99.19)$ & $30,337(99.34)$ \\
\hline & Drinking unboiled milk (yes) & $312(1.82)$ & $423(2.55)$ & $735(2.16)$ \\
\hline & Exposure to cold (no) & $12,894(79.22)$ & $11,124(80.12)$ & $24,018(79.64)$ \\
\hline \multirow{6}{*}{$\begin{array}{l}\text { Symptom/signs: } \\
\text { symptoms of a } \\
\text { person with TB }\end{array}$} & Persistent cough (>2 weeks) (yes) & $11,354(66.56)$ & $11,141(77.02)$ & $22,495(71.38)$ \\
\hline & Weight loss (yes) & $5,250(28.44)$ & $6,131(42.54)$ & $11,381(34.94)$ \\
\hline & Poor appetite (yes) & $1,870(9.304)$ & $1,940(15.15)$ & $3,810(12)$ \\
\hline & Night sweating (yes) & $905(3.7)$ & $853(4.16)$ & $1,758(3.91)$ \\
\hline & Chest pain (yes) & $1,033(6.16)$ & $1,020(5.57)$ & $2,053(5.89)$ \\
\hline & Fever (yes) & $2,121(9.16)$ & $1,974(9.99)$ & $4,095(9.54)$ \\
\hline Treatment & Tuberculosis can be cured (yes) & $12,564(79.8)$ & $12,302(89.45)$ & $\begin{array}{r}24,866 \\
(84.38) \\
\end{array}$ \\
\hline Attitude & Will keep TB patient in family a secret (no) & $10,724(72.12)$ & $11,025(81.25)$ & $21,749(76.47)$ \\
\hline
\end{tabular}

knew major symptoms of a person with tuberculosis: "night sweating" (3.7\% of females and $4.16 \%$ of males), "chest pain" (6.16\% of females and $5.57 \%$ of males), and "fever" (9.16\% of females and $9.99 \%$ of males) (Table 2 ). The most commonly identified TB symptom is "persistent cough" $(66.6 \%$ of females and 77.02 of males, overall: $71.38 \%)$. The majority of respondents $(84.38 \%)$ knew that "TB can be cured." And $76.47 \%$ said they will not "keep TB patients in family a secret."

3.3. Magnitude of Low TB Knowledge. The overall prevalence of low TB knowledge is high, with higher proportion among women, $44.05 \%$ (95\% CI: 42.05-46.24\%), compared to men, $32.3 \%$ (95\% CI: $30.34-34.32 \%$ ). Rural residents $(49.17 \%$ of females and $35.44 \%$ of males) have higher prevalence of low TB knowledge compared with urban residents (28.1\% among females and $21.11 \%$ among males). For both female and male respondents, the magnitude of low TB knowledge is higher among the youths (15-24 years) (46.17\%) compared with older age groups. Respondents from both hard to reach and accessible regions have similar level of low TB knowledge (Table 3).

\subsection{Socioeconomic Factors Associated with Low TB Knowledge}

3.4.1. Bivariate Analysis Results. At the bivariate analysis stage, the crude ORs showed that all the socioeconomic variables were significantly associated with low TB knowledge among both female and male study participants. After adjusting, all factors remained significant for females but residence, region, and occupation were not any more significantly associated with low TB knowledge in males (Tables 4 and 5).

3.4.2. Multivariate Analysis Results for Female Study Participants. Rural women are victims of having low TB knowledge. The odds of low TB knowledge was 1.22 (95\% CI: 1.06-1.41, $p=0.006)$ times higher among rural female residents as compared to urban residents. Being in the age groups 25$34,35-44$, and 45-49 was negatively associated with low TB knowledge compare with 15-24 years females, AORs being 0.68 (95\% CI: 0.62-0.75), 0.60 (95\% CI: 0.54-0.67), and 0.62 (95\% CI: $0.53-0.71)$, respectively, and $p<0.0001$ in all. Not having any formal education $(\mathrm{AOR}=3.28,95 \% \mathrm{CI}$ : 2.52-4.27, $p<0.0001$ ) and having attended only primary education $(\mathrm{AOR}=1.95,95 \% \mathrm{CI}: 1.51-2.51, p<0.0001)$ had increased odds of low TB knowledge as compared to women participants who have attended more than secondary school. The odds of low TB knowledge were higher among participants with lowest wealth quintiles, second, middle, and fourth wealth quintiles, as compared to those participants from highest wealth quartiles, AORs $=1.4$ (95\% CI: $1.20-$ $1.63, p<0.0001), 1.25$ (95\% CI: 1.07, 1.46, $p=0.005), 1.23$ (95\% CI: 1.06-1.44, $p=0.008$ ), and 1.17 (95\% CI: 1.01-1.35, $p=0.035)$, respectively. "Unskilled female manual workers," being "agricultural employee," those "not working," "skilled manual" worker, and "clerical/sales and service workers" were associated with increased odds of low TB knowledge compared with professional/technical/managerial female workers, AORs being 4.15 (95\% CI: 2.37-7.28, $p<0.0001$ ), 2.28 
TABLE 3: Prevalence of low comprehensive TB Knowledge, Ethiopia 2011.

\begin{tabular}{|c|c|c|c|c|c|}
\hline \multirow{2}{*}{ Characteristics } & \multirow{2}{*}{ Category } & \multicolumn{2}{|c|}{ Women } & \multicolumn{2}{|c|}{ Men } \\
\hline & & Prevalence & $95 \% \mathrm{CI}$ & Prevalence & $95 \% \mathrm{CI}$ \\
\hline National total & & 44.14 & $(42.05,46.24)$ & 32.3 & $(30.34,34.32)$ \\
\hline \multirow{2}{*}{ Residence } & Urban & 28.1 & $(24.55,31.95)$ & 21.11 & $(18.29,24.24)$ \\
\hline & Rural & 49.17 & $(46.69,51.66)$ & 35.44 & $(33.06,37.9)$ \\
\hline \multirow{4}{*}{ Age } & $15-24$ & 46.31 & $(43.74,48.9)$ & 39.92 & $(37.18,42.74)$ \\
\hline & $25-34$ & 42.57 & $(39.72,45.47)$ & 27.6 & $(25.24,30.08)$ \\
\hline & $35-44$ & 41.5 & $(38.37,44.71)$ & 27.19 & $(24.61,29.93)$ \\
\hline & $45-49$ & 45.36 & $(41.02,49.77)$ & 27.42 & $(23.27,32.0)$ \\
\hline \multirow{3}{*}{ Region } & Accessible regions & 45.4 & $(43.07,47.75)$ & 33.14 & $(30.97,35.37)$ \\
\hline & Hard to reach regions & 41.59 & $(8.09,45.18)$ & 34.31 & $(31.03,37.75)$ \\
\hline & City administrations & 27.51 & $(24.79,30.42)$ & 17.95 & $(14.34,22.23)$ \\
\hline \multirow{6}{*}{ Current marital status } & Never in union & 42.11 & $(39.4,44.87)$ & 36.87 & $(34.24,39.57)$ \\
\hline & Married & 44.66 & $(42.03,47.32)$ & 28.79 & $(26.66,31.02)$ \\
\hline & Living with partner & 42.96 & $(37.22,48.9)$ & 31.87 & $(24.1,40.8)$ \\
\hline & Widowed & 39.84 & $(34.23,45.73)$ & 37.95 & $(22.82,55.84)$ \\
\hline & Divorced & 52.83 & $(47.14,58.45)$ & 41.79 & $(33.78,50.27)$ \\
\hline & No longer living together/separated & 42.72 & $(35.54,50.21)$ & 22.6 & $(12.84,36.65)$ \\
\hline \multirow{4}{*}{ Education } & No education & 52.67 & $(50.01,55.32)$ & 44.01 & $(40.85,47.21)$ \\
\hline & Primary & 40.09 & $(37.68,42.56)$ & 31.16 & $(28.84,33.58)$ \\
\hline & Secondary & 22.41 & $(18.72,26.59)$ & 15.8 & $(13.16,18.85)$ \\
\hline & More than secondary & 13.99 & $(10.36,18.61)$ & 8.251 & $(6.038,11.18)$ \\
\hline \multirow{5}{*}{ Wealth quintile } & Lowest & 55.31 & $(51.78,58.8)$ & 42.7 & $(38.29,47.22)$ \\
\hline & Second & 50.77 & $(47,54.53)$ & 37.05 & $(33.63,40.61)$ \\
\hline & Middle & 49.63 & $(45.9,53.36)$ & 35.66 & $(32.09,39.39)$ \\
\hline & Fourth & 43.69 & $(40.33,47.11)$ & 30.15 & $(26.9,33.62)$ \\
\hline & Highest & 27.93 & $(24.86,31.23)$ & 20.67 & $(17.8,23.87)$ \\
\hline \multirow{6}{*}{ Occupation } & Professional/technical/managerial & 9.023 & $(5.007,15.73)$ & 7.766 & $(5.317,11.21)$ \\
\hline & Not working & 45.25 & $(42.51,48.01)$ & 34.94 & $(30.09,40.12)$ \\
\hline & Clerical/sales and services & 36.02 & $(33.35,38.78)$ & 24.66 & $(20.87,28.89)$ \\
\hline & Agricultural employee & 51.38 & $(48.06,54.7)$ & 35.84 & $(33.4,38.35)$ \\
\hline & Skilled manual & 41.52 & $(35.84,47.44)$ & 21.01 & $(17.13,25.5)$ \\
\hline & Unskilled manual & 55.6 & $(47.14,63.74)$ & 29.98 & $(20.37,41.73)$ \\
\hline \multirow{2}{*}{$\begin{array}{l}\text { Exposure to mass } \\
\text { media }\end{array}$} & Accesses none of the three media at least once a week & 57.17 & $(54.52,59.77)$ & 50.75 & $(46.78,54.72)$ \\
\hline & Accesses either newspaper, TV, or radio at least once a week & 37.87 & $(35.66,40.14)$ & 28.31 & $(26.41,30.3)$ \\
\hline \multirow{2}{*}{$\begin{array}{l}\text { Heard of community } \\
\text { conversation program }\end{array}$} & No & 50.1 & $(47.62,52.58)$ & 42.1 & $(39.45,44.79)$ \\
\hline & Yes & 30.71 & $(28.51,32.99)$ & 23.35 & $(21.24,25.59)$ \\
\hline
\end{tabular}

(95\% CI: 1.44-3.60, $p<0.001), 1.96$ (95\% CI: 1.25-3.08, $p=0.004), 1.81$ (95\% CI: 1.13-2.89, $p=0.013$ ), and 1.70 (95\% CI: 1.08-2.67, 0.023), respectively. Female participants who had no access to newspaper, television, or radio had 1.52 (95\% CI: $1.41-1.64, p \leq 0.0001$ ) times increasing odds of low TB knowledge as compared to those who had access to either of the three media at least once a week (Tables 4 and 5).
3.4.3. Multivariate Analysis Results for Male Study Participants. Not having any formal education and having attended primary education and secondary education had increased odds of having low TB knowledge as compared to male participants who have attended more than secondary school, AORs being 7.42 (95\% CI: 5.70-9.66, $p<0.0001$ ), 3.49 (95\% CI: 2.71-4.48, $p<0.0001$ ), and 1.55 (95\% CI: 1.17-2.05, 
TABLE 4: Factors associated with low TB knowledge among women, Ethiopia 2011.

\begin{tabular}{|c|c|c|c|c|c|c|}
\hline Characteristics & Category & $\begin{array}{c}\text { Low knowledge } \\
n(\%)\end{array}$ & $\begin{array}{c}\text { Crude OR } \\
(95 \% \text { CI })\end{array}$ & $\begin{array}{l}p \text { value } \\
\text { (crude) }\end{array}$ & $\begin{array}{c}\text { Adjusted OR } \\
(95 \% \mathrm{CI})\end{array}$ & $\begin{array}{c}p \text { value } \\
\text { (adjusted) }\end{array}$ \\
\hline \multirow{2}{*}{ Residence } & Urban & $1,344(28.1)$ & 1 & & 1 & \\
\hline & Rural & $5,253(49.17)$ & $2.48(2.01,3.05)$ & $<0.0001$ & $1.22(1.06,1.41)$ & 0.006 \\
\hline \multirow{4}{*}{ Age } & $15-24$ & $2,907(46.31)$ & 1 & & 1 & \\
\hline & $25-34$ & $2,057(42.57)$ & $0.86(0.76,0.97)$ & 0.016 & $0.68(0.62,0.75)$ & $<0.0001$ \\
\hline & $35-44$ & $1,212(41.5)$ & $0.82(0.71,0.95)$ & 0.010 & $0.60(0.54,0.67)$ & $<0.0001$ \\
\hline & $45-49$ & $421(45.36)$ & $0.96(0.80,1.16)$ & 0.688 & $0.62(0.53,0.71)$ & $<0.0001$ \\
\hline \multirow{6}{*}{ Current marital status } & Never in union & $1,673(42.11)$ & 1 & & 1 & \\
\hline & Married & $3,897(44.66)$ & $1.11(0.96,1.28)$ & 0.152 & $0.82(0.74,0.91)$ & $<0.0001$ \\
\hline & Living with partner & $275(42.96)$ & $1.04(0.80,1.34)$ & 0.787 & $0.92(0.77,1.10)$ & 0.362 \\
\hline & Widowed & $216(39.84)$ & $0.91(0.71,1.17)$ & 0.465 & $0.75(0.61,0.93)$ & 0.009 \\
\hline & Divorced & $400(52.83)$ & $1.54(1.21,1.96)$ & $<0.0001$ & $1.22(1.04,1.44)$ & 0.017 \\
\hline & No longer living together/separated & $136(44.14)$ & $1.03(0.75,1.40)$ & 0.876 & $1.03(0.81,1.32)$ & 0.807 \\
\hline \multirow{3}{*}{ Region } & Accessible regions & $3,578(45.4)$ & $2.19(1.85,2.60)$ & $<0.0001$ & $0.91(0.77,1.08)$ & 0.293 \\
\hline & Hard to reach regions & $2,013(41.59)$ & $1.88(1.53,2.30)$ & $<0.0001$ & $0.68(0.54,0.85)$ & 0.001 \\
\hline & City administrations & $1,006(27.51)$ & 1 & & 1 & \\
\hline \multirow{4}{*}{ Education } & No education & $4,013(52.67)$ & $6.84(4.80,9.76)$ & $<0.0001$ & $3.28(2.52,4.27)$ & $<0.0001$ \\
\hline & Primary & $2,227(40.09)$ & $4.12(2.94,5.76)$ & $<0.0001$ & $1.95(1.51,2.51)$ & $<0.0001$ \\
\hline & Secondary & $260(22.41)$ & $1.78(1.23,2.56)$ & 0.002 & $1.17(0.89,1.55)$ & 0.261 \\
\hline & More than secondary & 97 (13.99) & 1 & & 1 & \\
\hline \multirow{5}{*}{ Wealth quintile } & Lowest & $1,873(55.31)$ & $3.19(2.59,3.94)$ & $<0.0001$ & $1.40(1.20,1.63)$ & $<0.0001$ \\
\hline & Second & $1,162(50.77)$ & $2.66(2.14,3.31)$ & $<0.0001$ & $1.25(1.07,1.46)$ & 0.005 \\
\hline & Middle & $1,094(49.63)$ & $2.541(2.05,3.15)$ & $<0.0001$ & $1.23(1.06,1.44)$ & 0.008 \\
\hline & Fourth & $1,058(43.69)$ & $2.00(1.66,2.42)$ & $<0.0001$ & $1.17(1.01,1.35)$ & 0.035 \\
\hline & Highest & $1,410(27.93)$ & 1 & & 1 & \\
\hline
\end{tabular}

TABLE 5: Factors associated with low TB knowledge among women, Ethiopia 2011, continued.

\begin{tabular}{|c|c|c|c|c|c|c|}
\hline Characteristics & Category & $\begin{array}{c}\text { Low } \\
\text { knowledge } \\
n(\%)\end{array}$ & $\begin{array}{l}\text { Crude OR }(95 \% \\
\text { CI })\end{array}$ & $\begin{array}{l}p \text { value } \\
\text { (crude) }\end{array}$ & $\begin{array}{l}\text { Adjusted OR } \\
(95 \% \mathrm{CI})\end{array}$ & $\begin{array}{l}p \text { value } \\
\text { (adjusted) }\end{array}$ \\
\hline \multirow{6}{*}{ Occupation } & Professional/technical/managerial & $27(9.02)$ & 1 & & 1 & \\
\hline & Not working & $\begin{array}{c}3,292 \\
(45.25)\end{array}$ & $8.33(4.45,15.58)$ & $<0.0001$ & $1.96(1.25,3.09)$ & 0.004 \\
\hline & Clerical/sales and services & $1,138(36.02)$ & $5.68(3.01,10.69)$ & $<0.0001$ & $1.70(1.08,2.67)$ & 0.023 \\
\hline & Agricultural employee & $1,531(51.38)$ & $10.66(5.58,20.35)$ & $<0.0001$ & $2.28(1.44,3.60)$ & $<0.0001$ \\
\hline & Skilled manual & $490(41.52)$ & $7.16(3.63,14.14)$ & $<0.0001$ & $1.81(1.13,2.89)$ & 0.013 \\
\hline & Unskilled manual & $57(55.6)$ & $12.62(6.14,25.96)$ & $<0.0001$ & $4.15(2.37,7.28)$ & $<0.0001$ \\
\hline \multirow[b]{2}{*}{ Exposure to mass media } & $\begin{array}{l}\text { Accesses none of the three media at } \\
\text { least once a week }\end{array}$ & $2,987(57.17)$ & $2.19(1.96,2.44)$ & $<0.0001$ & $1.52(1.41,1.64)$ & $<0.0001$ \\
\hline & $\begin{array}{l}\text { Accesses either newspaper, TV, or } \\
\text { radio at least once a week }\end{array}$ & $3,585(37.87)$ & 1 & & 1 & \\
\hline \multirow{2}{*}{$\begin{array}{l}\text { Heard of community } \\
\text { conversation program }\end{array}$} & No & $5,203(50.1)$ & $2.27(1.99,2.57)$ & $<0.0001$ & $1.63(1.52,1.76)$ & $<0.0001$ \\
\hline & Yes & $1,385(30.71)$ & 1 & & 1 & \\
\hline Final model fit & \multicolumn{6}{|c|}{ Pseudo- $R^{2}=0.08$, Log Likelihood $=-10360.78$, LR $\chi^{2}(25)=1680.62, p<0.0001$} \\
\hline
\end{tabular}

$p=0.002)$, respectively. The odds of low TB knowledge were higher among participants with lowest and middle wealth quintiles as compared to those participants from highest wealth quintile, AORs being 1.28 (95\% CI: 1.11-1.48, $p=$
$0.001)$ and 1.19 (95\% CI: $1.03-1.36, p=0.015$ ), respectively. Male participants who had no access to newspaper, television, or radio had 1.71 (95\% CI: 1.54-1.90, $p<0.0001)$ times higher odds of low TB knowledge as compared to those who had 
TABLE 6: Factors associated with low TB knowledge among men, Ethiopia 2011.

\begin{tabular}{|c|c|c|c|c|c|c|}
\hline Characteristics & Category & $\begin{array}{c}\text { Low knowledge } \\
n(\%)\end{array}$ & $\begin{array}{c}\text { Crude OR } \\
(95 \% \text { CI }) \\
\end{array}$ & $\begin{array}{l}p \text { value } \\
\text { (crude) }\end{array}$ & $\begin{array}{c}\text { Adjusted OR } \\
(95 \% \mathrm{CI})\end{array}$ & $\begin{array}{c}p \text { value } \\
\text { (adjusted) }\end{array}$ \\
\hline \multirow{2}{*}{ Residence } & Urban & $664(21.11)$ & 1 & & & \\
\hline & Rural & $3,477(35.44)$ & $2.05(1.67,2.53)$ & $<0.0001$ & & \\
\hline \multirow{4}{*}{ Age } & $15-24$ & $1,871(39.92)$ & 1 & & 1 & \\
\hline & $25-34$ & $1,010(27.6)$ & $0.57(0.51,0.65)$ & $<0.0001$ & $0.59(0.52,0.68)$ & $<0.0001$ \\
\hline & $35-44$ & $679(27.19)$ & $0.56(0.49,0.65)$ & $<0.0001$ & $0.54(0.46,0.63)$ & $<0.0001$ \\
\hline & $45-49$ & $244(27.42)$ & $0.57(0.46,0.71)$ & $<0.0001$ & $0.49(0.40,0.60)$ & $<0.0001$ \\
\hline \multirow{6}{*}{$\begin{array}{l}\text { Current marital } \\
\text { status }\end{array}$} & Never in union & $1,833(36.87)$ & 1 & & 1 & \\
\hline & Married & $2,061(28.79)$ & $0.69(0.62,0.78)$ & $<0.0001$ & $0.73(0.64,0.84)$ & $<0.0001$ \\
\hline & Living with partner & $100(31.87)$ & $0.80(0.54,1.20)$ & 0.280 & $1.17(0.87,1.57)$ & 0.307 \\
\hline & Widowed & $22(37.95)$ & $1.05(0.51,2.17)$ & 0.901 & $0.74(0.35,1.60)$ & 0.447 \\
\hline & Divorced & $99(41.79)$ & $1.23(0.87,1.74)$ & 0.245 & $1.14(0.84,1.54)$ & 0.400 \\
\hline & No longer living together/separated & $26(22.6)$ & $0.50(0.25,1.00)$ & 0.050 & $0.57(0.34,0.96)$ & 0.033 \\
\hline \multirow{3}{*}{ Region } & Accessible regions & $2,410(33.14)$ & $2.27(1.70,3.01)$ & $<0.0001$ & & \\
\hline & Hard to reach regions & $1,319(34.31)$ & $2.39(1.76,3.24)$ & $<0.0001$ & & \\
\hline & City administrations & $412(17.95)$ & 1 & 1 & & \\
\hline \multirow{4}{*}{ Education } & No education & $1,834(44.01)$ & $8.74(6.14,12.44)$ & $<0.0001$ & $7.42(5.70,9.66)$ & $<0.0001$ \\
\hline & Primary & $1,989(31.16)$ & $5.03(3.54,7.16)$ & $<0.0001$ & $3.49(2.71,4.48)$ & $<0.0001$ \\
\hline & Secondary & $224(15.8)$ & $2.09(1.39,3.13)$ & $<0.0001$ & $1.55(1.17,2.05)$ & 0.002 \\
\hline & More than secondary & $94(8.251)$ & 1 & & 1 & \\
\hline \multirow{5}{*}{ Wealth quintile } & Lowest & $1,144(42.7)$ & $2.86(2.21,3.70)$ & $<0.0001$ & $1.28(1.11,1.48)$ & 0.001 \\
\hline & Second & $785(37.05)$ & $2.26(1.78,2.87)$ & $<0.0001$ & $1.06(0.92,1.22)$ & 0.390 \\
\hline & Middle & $768(35.66)$ & $2.13(1.67,2.71)$ & $<0.0001$ & $1.19(1.03,1.36)$ & 0.015 \\
\hline & Fourth & $723(30.15)$ & $1.66(1.31,2.09)$ & $<0.0001$ & $1.01(0.89,1.16)$ & 0.828 \\
\hline & Highest & $721(20.67)$ & 1 & & 1 & \\
\hline
\end{tabular}

access to either of the three media at least once a week. The adjusted ORs for residence, occupation, and region did not show association in men and were excluded by the forward regression (Tables 6 and 7 ).

\section{Discussion}

In this study, though awareness of tuberculosis is high, specific knowledge on TB transmissions and symptoms is very low. Some major misconceptions on TB transmission are identified. The prevalence of low TB knowledge is high in the general adult population of Ethiopia, with higher magnitude among females than among males.

Rural women, younger people, less educated people, people from low socioeconomic status, those who have no access to mass media, and those who never heard of community conversation program on health and related topics have higher odds of low TB knowledge.

The level of low TB knowledge in the population in this study is in line with other small scale similar studies in different parts of Ethiopia $[9,14,21,22]$ and with studies done in other African countries and Asia [15, 16, 23, 30]. The high prevalence of low TB knowledge in the general population of Ethiopia might indicate that the current information and health education on TB is not sufficient and it is not properly addressing the target population. The situation is also exacerbated by the fact that majority of the population in Ethiopia live in low socioeconomic status and majority are from rural area $(86.8 \%)$, with high rate of no formal education or only primary education ( $41.6 \%$ and $40.9 \%)$, no formal work $(30.3 \%)$ or being only agricultural employees $(38.3 \%)$, with lowest wealth index $(21.4 \%)$, and no regular access to media $(26.4 \%)$, or having not heard of community conversation (58.7\%), which in turn are associated with low level of TB knowledge. As shown in the study by Gele et al. [18] and another study by Demissie et al. [17], low knowledge on TB is significantly associated with patient delay to seek health care, which is one of the major obstacles for controlling TB.

The finding regarding high misconception on TB transmission is comparable with other similar studies done in Africa and Asia [16, 31]. Understanding the misconceptions is very important as it might be the indication of the presence for delay of proper health seeking and refusal to take the right treatment decision and adherence to treatment. Misconception also may lead to stigma, which creates difficulty in engaging the community in TB control programs $[11,13]$. Health education programs on TB need to address the common misconceptions in the community. 
TABLE 7: Factors associated with low TB knowledge among Men, Ethiopia 2011, continued.

\begin{tabular}{|c|c|c|c|c|c|c|}
\hline Characteristics & Category & $\begin{array}{c}\text { Low } \\
\text { knowledge } \\
n(\%)\end{array}$ & $\begin{array}{l}\text { Crude OR }(95 \% \\
\text { CI) }\end{array}$ & $\begin{array}{l}p \text { value } \\
\text { (crude) }\end{array}$ & $\begin{array}{l}\text { Adjusted OR } \\
\quad(95 \% \mathrm{CI})\end{array}$ & $\begin{array}{l}p \text { value } \\
\text { (adjusted) }\end{array}$ \\
\hline \multirow{6}{*}{ Occupation } & Professional/technical/managerial & $63(7.77)$ & 1 & & & \\
\hline & Not working & $340(34.94)$ & $6.38(4.03,10.08)$ & $<0.0001$ & & \\
\hline & Clerical/sales and services & $403(24.66)$ & $3.89(2.44,6.19)$ & $<0.0001$ & & \\
\hline & Agricultural employee & $\begin{array}{c}3,030 \\
(35.84)\end{array}$ & $6.63(4.42,9.96)$ & $<0.0001$ & & \\
\hline & Skilled manual & $201(21.01)$ & $3.16(1.99,5.02)$ & $<0.0001$ & & \\
\hline & Unskilled manual & $64(29.98)$ & $5.08(2.69,9.60)$ & $<0.0001$ & & \\
\hline \multirow{2}{*}{ Exposure to mass media } & $\begin{array}{l}\text { Accesses none of the three media at } \\
\text { least once a week }\end{array}$ & $\begin{array}{c}1,096 \\
(50.75)\end{array}$ & $2.61(2.23,3.05)$ & $<0.0001$ & $1.71(1.54,1.90)$ & $<0.0001$ \\
\hline & $\begin{array}{l}\text { Accesses either newspaper, TV, or } \\
\text { radio at least once a week }\end{array}$ & $3,027(28.31)$ & 1 & & 1 & \\
\hline \multirow{2}{*}{$\begin{array}{l}\text { Heard of community } \\
\text { conversation program }\end{array}$} & No & $5,203(42.1)$ & $2.39(2.10,2.71)$ & $<0.0001$ & $1.71(1.57,1.85)$ & $<0.0001$ \\
\hline & Yes & $1,385(23.35)$ & 1 & & 1 & \\
\hline Final model fit & \multicolumn{6}{|c|}{ Pseudo- $R^{2}=0.104$, Log Likelihood $=-7164.00$, LR $\chi^{2}(17)=1655.86, p<0.0001$} \\
\hline
\end{tabular}

The fact that the rural women are highly affected with low TB knowledge compared to urban women could be due to the fact that the majority of rural women in Ethiopia are housewives confined to household activities with fewer outside social interaction compared to male in the society. They are also exposed to different economic, cultural, geographical barriers to get access to proper information. Similar findings from North Ethiopia were reported by Mesfin [21] and other study from Vietnam [32]. Addressing the rural women will contribute to the success of the TB control program.

The poor (low wealth quintile) have high prevalence of low comprehensive TB knowledge and it is in line with the study from India [16]. As proved by the study from Manila [15], people with low income have association with low health seeking behavior. The low level of knowledge among the poor in our study worsens the low level of health seeking behavior among the poor [17]. The burden of TB is high among the poor with deprived living conditions, malnutrition, and exposure to other communicable diseases. The lack of knowledge on TB in this community will aggravate the situation as they will not know how to protect themselves from the disease, when to seek health care, the need for treatment, and the importance of adherence to treatment for TB. As a result, these would in turn create difficulty to have effective TB control program. The poor need to be addressed in the health education and information on TB and addressing the problems of the poor will contribute to the effectiveness of $\mathrm{TB}$ control programs.

Education is highly associated with the level of comprehensive TB knowledge, and the uneducated people and those who had only primary education had high odds of low comprehensive knowledge. This finding was supported by similar other studies $[9,15,21,23,33]$. The explanation might be that the educated people have more access to different sources of information and easily understand more complex messages. Increasing the level of education in the community will increase the general knowledge about infection control including $\mathrm{TB}$ and the general health of the people.

Access to mass media is an important factor associated with TB knowledge. Those study participants who have access to either newspaper, TV, or radios at least once a week had better TB knowledge. Increasing the access to mass media and community health education in TB control through mass media can play a key role in creating awareness and building knowledge on TB. This may encourage individuals to seek health care on timely fashion, to adhere to treatment to protect them from $\mathrm{TB}$ which will contribute in all over reduction of prevalence of TB.

The secondary data analysis employed in this study could have been influenced by any unknown limitations related to the primary data method of data collection and sampling procedures.

Some variables which may have effect on TB knowledge and at the same time which were not collected in the primary data are not analysed in the current study. There might also be unmeasured confounding factors affecting TB knowledge as primary data was collected for a different purpose. The TB knowledge questions collected in the primary data were not complete. Information such as knowledge on TB prevention methods and importance of adherence to treatment could have been included.

Moreover, the composite index of low TB knowledge was taken from ten variables after doing factor analysis for consistency. Due to the small number of variables included in the index construction, the Chronbach Alpha was relatively in the lower border. Including more TB prevention knowledge items such as ventilation of the households, avoiding overcrowding, avoiding of spiting in all places, protecting people from directly coughing and sneezing, and importance of using mask for contacts with infectious TB patients may increase the reliability of the overall index. 


\section{Conclusion and Recommendation}

The result from this study produced useful information for policy makers to evaluate and shape the TB control programs and plan socioeconomic and public health measures to increase TB knowledge and further enhance the TB control programs.

Public health measures should thus focus on enhancing the health education to address the most affected population group and increase the level of TB knowledge among the general population. The education materials need to be target oriented and incorporate the basic knowledge gaps such as concepts on TB transmission, TB major symptoms, curability, prevention methods, and the importance of treatment, at the same time of addressing the misconceptions. Increasing the use of multiple mass media sources would help to improve the health education coverage and address the target populations. Increasing the regular education coverage to the population and incorporating TB to school curriculum would especially address the uneducated and the in-school youths. Most importantly, tuberculosis control programs and intervention prioritizations should consider appropriate strategies for tuberculosis education, promotion, communication, and social mobilization to address the rural women, the youth, the poor, less educated people, and unskilled workers. Additionally, the depth of the magnitude of the problem needs to be addressed by socioeconomic measures such as empowering rural women to make their own decision and to get access to information and reformulating poverty reduction strategies to improve the socioeconomic status of the people.

Further large scale study is recommended to address the unmeasured confounders and additional TB knowledge questions.

\section{Conflict of Interests}

The author declares that there is no conflict of interests regarding the publication of this paper.

\section{Acknowledgments}

The author would like to highly acknowledge Mr. Alexander Rommel for his kind support during the study. The author would also like to thank her husband Professor Alemayehu Worku Yalew for his support and encouragement.

\section{References}

[1] N. Noah, “Tuberculosis. Controlling communicable disease. EnglandSL6 2QL, and Two Penn Plaza, New York, NY 101212289, USA," in Understanding Public Health, pp. 157-170, Open University Press, London School of Hygiene \& Tropical Medicine, 2006.

[2] M. S. Jassal and W. R. Bishai, "Epidemiology and challenges to the elimination of global tuberculosis," Clinical Infectious Diseases, vol. 50, supplement 3, pp. S156-S164, 2010.

[3] Central Statistical Agency of Ethiopia and ICF International, Ethiopia Demographic and Health Survey 2011, MEASURE
DHS Demographic and Health Surveys, Calverton, NY, USA, 2012, http://measuredhs.com/pubs/pdf/FR255/FR255.pdf, http://dhsprogram.com/Where-\%20We-Work/Country\%20Main. $\mathrm{cfm}$ ?ctry_id=65\&c=Ethiopia\&Country=Ethiopia\&cn $=\& \mathrm{r}=1$.

[4] CSA Ethiopia, National Statistical Abstract,Population 2014, Central Statistical Agency of Ethiopia, Addis Ababa, Ethiopia, 2012, http://www.csa.gov.et/index.php/2013-02-20-13-43-35/ national-statistics-abstract/141-population.

[5] WHO, Global Tuberculosis Control WHO Report 2011, WHO, Geneva, Switzerland, 2011, http://whqlibdoc.who.int/ publications/2011/9789241564380_eng.pdf.

[6] WHO, Tuberculosis. Global Tuberculosis Report 2012, WHO, Geneva, Switzerland, 2012, http://www.who.int/tb/publications/global_report/en/.

[7] Health Sector Development Programme IV Version 1, Annual Performance Report EFY 2003(2010/11), Ministry of Health of Federal Democratic Republic of Ethiopia, http://www.moh.gov.et/mwginternal/de5fs23hu73ds/progress?id= 01qXHAb3CFDfsKf8GSMVCX7DhByQ8AysmcUH2iz6doM,\&dl.

[8] WHO, WHO and Stop TB Strategy, Building on and Enhancing DOTS to Meet the TB-Related Millennium Development Goals, World Health Organization, Geneva, Switzerland, 2006, http://apps.who.int/iris/bitstream/10665/69241/1/WHO_HTM_ STB_2006.368_eng.pdf.

[9] R. Abebe and M. Demissie, "Assessment of knowledge and practices related to tuberculosis and associated factors among HIV positive people in Addis Ababa, Ethiopia," Global Journal of Medicine and Public Health, vol. 1, no. 2, 2012, http://www.gjmedph.org/.

[10] E. B. Shargie and B. Lindtjørn, "Determinants of treatment adherence among smear-positive pulmonary tuberculosis patients in Southern Ethiopia," PLoS Medicine, vol. 4, no. 2, aticle e37, 2007.

[11] HATiP HIV \& AIDS treatment in practice: TB/HIV treatment literacy, Issue 153/February 2010, http://www.aidsmap.com/.

[12] BC Strategic Plan for Tuberculosis Prevention, Treatment and Control, BC Communicable Disease Policy Advisory Committee, British Columbia, Canada, 2012.

[13] Fighting TB on the front lines: highlights and recommendations from the Stop-TB eForum 2005. A joint publication of Health and Development Networks and the AIDS-Care-Watch Campaign, Health and Development Networks, 2005.

[14] D. S. Abebe, D. Biffa, G. Bjune, G. Ameni, and F. Abebe, "Assessment of knowledge and practice about tuberculosis among eastern Ethiopian prisoners," International Journal of Tuberculosis and Lung Disease, vol. 15, no. 2, pp. 228-233, 2011.

[15] J. L. Portero Navio, M. Rubio Yuste, and M. A. Pasicatan, "Socio-economic determinants of knowledge and attitudes about tuberculosis among the general population of Metro Manila, Philippines," The International Journal of Tuberculosis and Lung Disease, vol. 6, no. 4, pp. 301-306, 2012.

[16] C. T. Sreeramareddy, H. N. Harsha Kumar, and J. T. Arokiasamy, "Prevalence of self-reported tuberculosis, knowledge about tuberculosis transmission and its determinants among adults in India: results from a nation-wide cross-sectional household survey," BMC Infectious Diseases, vol. 13, article 16, 2013.

[17] M. Demissie, B. Lindtjorn, and Y. Berhane, "Patient and health service delay in the diagnosis of pulmonary tuberculosis in Ethiopia," BMC Public Health, vol. 2, article 23, 2002.

[18] A. A. Gele, G. Bjune, and F. Abebe, "Pastoralism and delay in diagnosis of TB in Ethiopia," BMC Public Health, vol. 9, article 5, 2009. 
[19] M. Belay, G. Bjune, G. Ameni, and F. Abebe, "Diagnostic and treatment delay among Tuberculosis patients in Afar Region, Ethiopia: a cross-sectional study," BMC Public Health, vol. 12, no. 1, article 369, 2012.

[20] D. G. Storla, S. Yimer, and G. A. Bjune, "A systematic review of delay in the diagnosis and treatment of tuberculosis," BMC Public Health, vol. 8, article 15, 2008.

[21] M. M. Mesfin, T. W. Tasew, I. G. Tareke, G. W. Mulugeta, and M. J. Richard, "Community knowledge, attitudes and practices on pulmonary tuberculosis and their choice of treatment supervisor in Tigray, Northern Ethiopia," Ethiopian Journal of Health Development, vol. 19, 2005.

[22] M. Legesse, G. Ameni, G. Mamo et al., "Knowledge and perception of pulmonary tuberculosis in pastoral communities in the middle and lower awash valley of afar region, Ethiopia," BMC Public Health, vol. 10, article 187, 2010.

[23] A. I. Mohamed, M. A. Yousif, P. Ottoa, and A. Bayoumi, "Knowledge of tuberculosis. A survey among tuberculosis patients in Omdurman, Sudan," Sudanese Journal of Public Health, vol. 2, no. 1, 2007.

[24] E. Kiefer, T. Shao, O. Carasquillo, P. Nabeta, and C. Seas, "Knowledge and attitudes of tuberculosis management in San Juan de Lurigancho district of Lima, Peru," Journal of Infection in Developing Countries, vol. 3, no. 10, pp. 783-788, 2009.

[25] M. A. Solliman, M. A. Hassali, M. Al-Haddad et al., "Assessment of knowledge towards tuberculosis among general population in North East Libya," Journal of Applied Pharmaceutical Science, vol. 2, no. 4, pp. 24-30, 2012.

[26] C. Gilpin, P. de Colombani, S. Hasanova, and U. Sirodjiddinova, "Exploring TB-related knowledge, attitude, behaviour, and practice among migrant workers in Tajikistan," Tuberculosis Research and Treatment, vol. 2011, Article ID 548617, 10 pages, 2011.

[27] M. Renuka and M. Dhar, "Knowledge and awareness of tuberculosis among high school students of Mysore City," Al Ameen Journal of Medical Sciences, vol. 5, no. 3, pp. 333-336, 2012.

[28] S. X. Jittimanee, S. Nateniyom, W. Kittikraisak et al., "Social stigma and knowledge of tuberculosis and HIV among patients with both diseases in Thailand," PLoS ONE, vol. 4, no. 7, Article ID e6360, 2009.

[29] A. A. Fatiregun and C. C. Ejeckam, "Determinants of patient delay in seeking treatment among pulmonary tuberculosis cases in a government specialist hospital in Ibadan, Nigeria," Tanzania Journal of Health Research, vol. 12, no. 2, 2010.

[30] P. Mweemba, C. Haruzirishe, S. Siziya et al., "Knowledge, attitude, compliance with TB treatment, Lusaka, Zambia," Medical Journal of Zambia, vol. 35, no. 4, 2008.

[31] J. A. Khan, M. Irfan, A. Zaki, M. Beg, S. F. Hussain, and N. Rizvi, "Knowledge, attitude and misconceptions regarding tuberculosis in Pakistani patients," Journal of the Pakistan Medical Association, vol. 56, no. 2, pp. 211-214, 2006.

[32] N. P. Hoa, A. E. K. Thorson, N. H. Long, and V. K. Diwan, "Knowledge of tuberculosis and associated health-seeking behaviour among rural Vietnamese adults with a cough for at least three weeks," Scandinavian Journal of Public Health, vol. 31, no. 6, supplement, pp. 59-65, 2003.

[33] E. A. Obuku, C. Meynell, J. Kiboss-Kyeyune et al., "Sociodemographic determinants and prevalence of Tuberculosis knowledge in three slum populations of Uganda," BMC Public Health, vol. 12, article 536, 2012. 


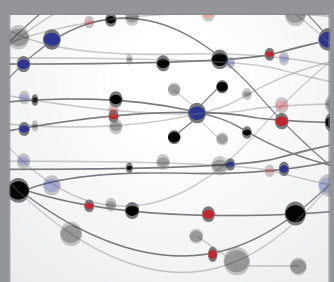

The Scientific World Journal
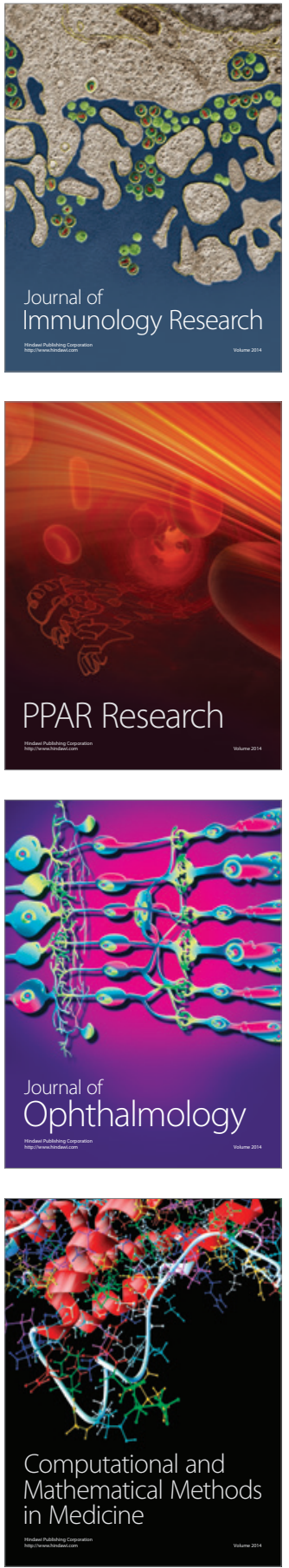

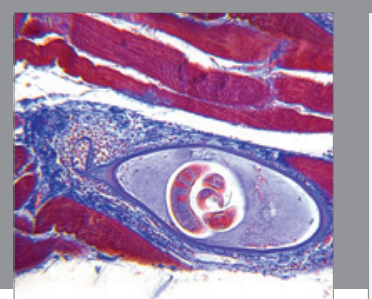

Gastroenterology Research and Practice

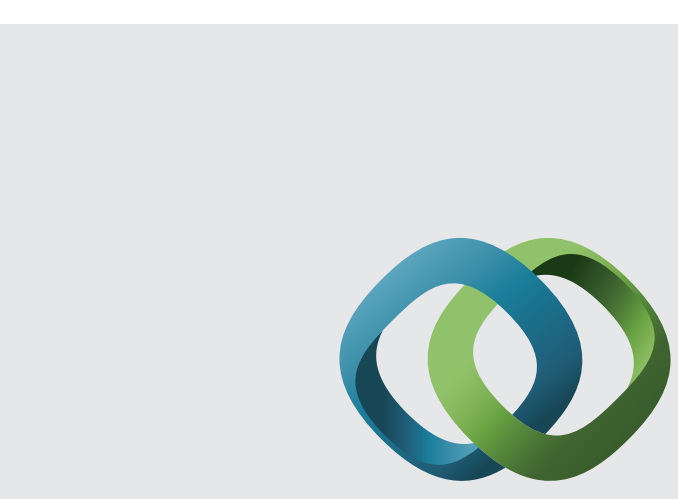

\section{Hindawi}

Submit your manuscripts at

http://www.hindawi.com
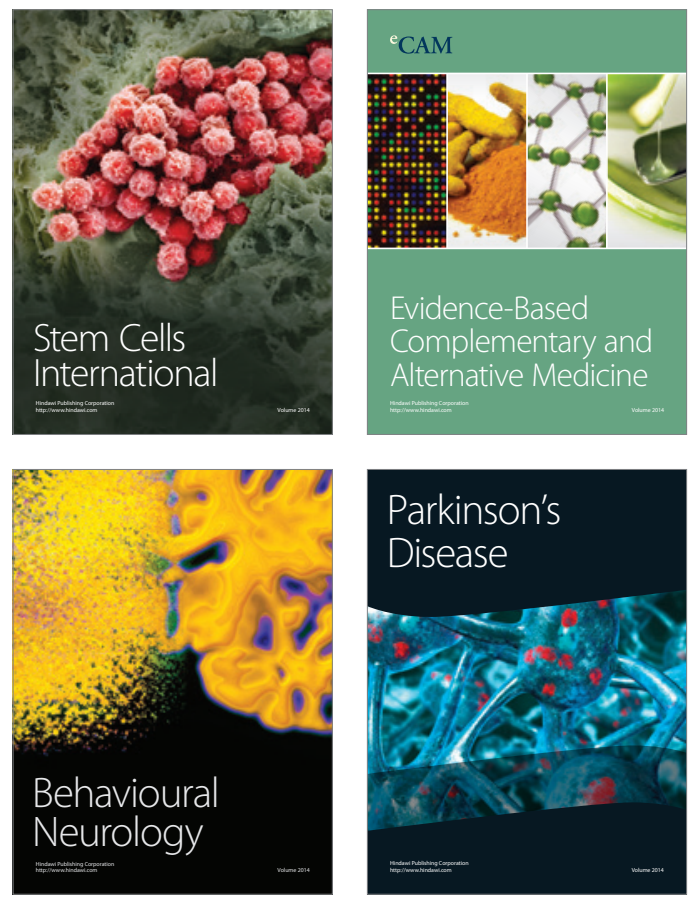
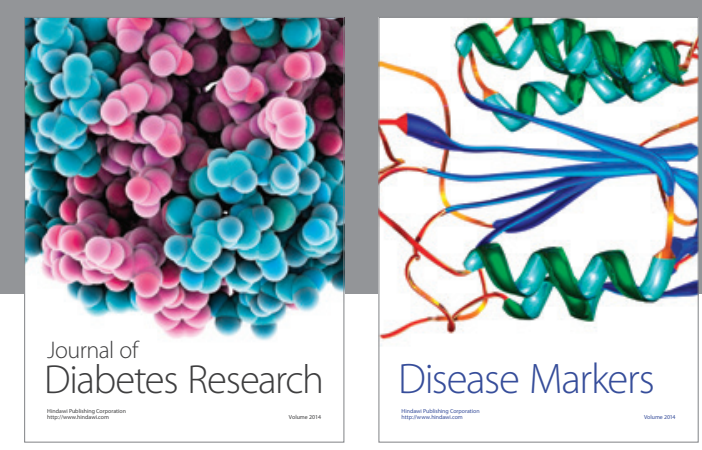

Disease Markers
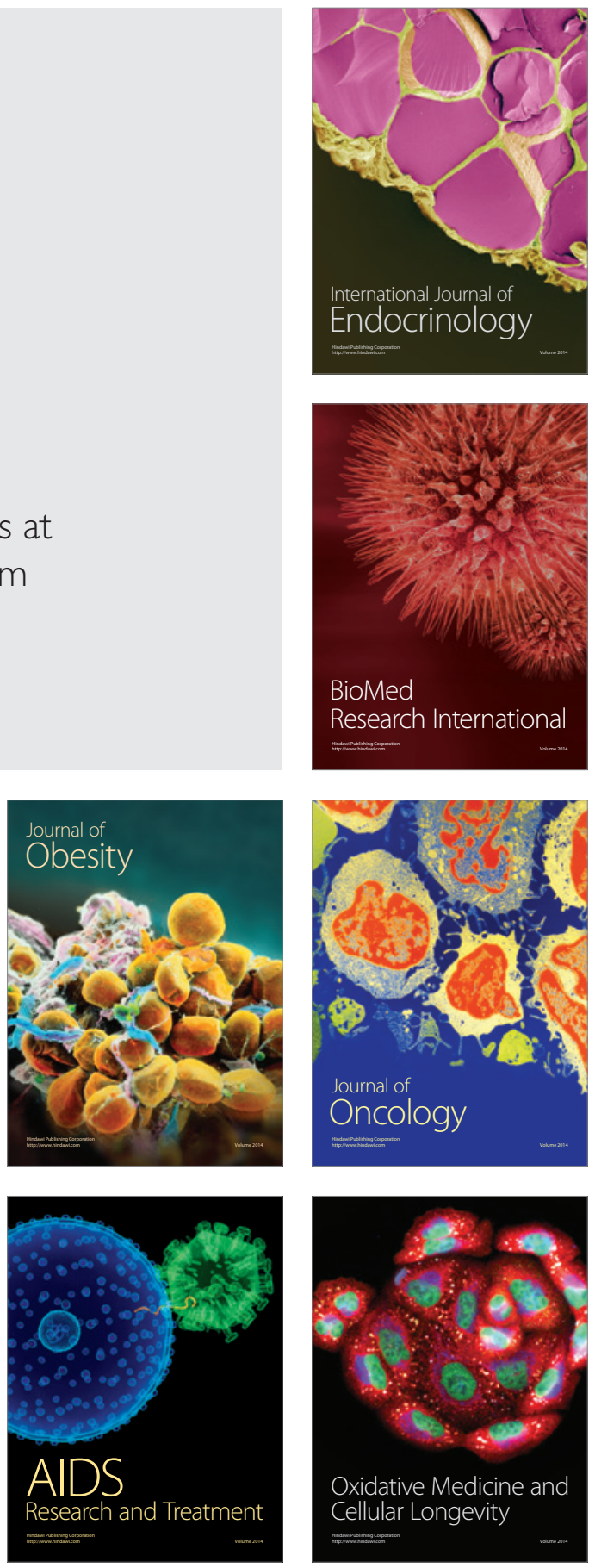